\title{
COLABORAÇÃO REMOTA NO PROJETO DE ARQUITETURA E URBANISMO EM UM CONTEXTO DE ISOLAMENTO SOCIAL
}

\author{
COLABORACIÓN REMOTA EN DISEÑO DE ARQUITECTURA Y URBANISMO EN UN CONTEXTO DE \\ AISLAMIENTO SOCIAL
}

\section{REMOTE COLLABORATION IN ARCHITECTURAL AND URBAN DESIGN IN A SOCIAL ISOLATION CONTEXT}

\section{CELANI, GABRIELA}

PhD, Unicamp, celani@unicamp.br

\section{INTRODUÇÃO}

Durante a pandemia da COVID19, tivemos de aprender a ensinar e a colaborar remotamente. Isso se mostrou particularmente desafiador no caso das disciplinas de projeto de Arquitetura e Urbanismo, em que tipicamente os alunos interagem em um grande atelier. Mas a colaboração remota em projetos não é um assunto novo. Desde o final dos anos 1990, já havia um interesse em aprofundar este método, tendo como motivação a internacionalização do ensino e do trabalho dos arquitetos, ampliando seus horizontes e sua visão de mundo. Neste artigo, são relatadas primeiramente algumas dessas primeiras experiências e, em seguida, a experiência da própria autora no ensino remoto em 2020. Espera-se que este relato contribua com um novo olhar para esta situação forçada - e muitas vezes incômoda - que estamos vivenciando, mas que pode ter alguns aspectos positivos que poderão ser mantidos no futuro.

\section{AS PRIMEIRAS EXPERIÊNCIAS DE PROJETO COLABORATIVO REMOTO NO MIT}

Em 1995, William J. Mitchell, professor do MIT e um dos pioneiros do uso de novas tecnologias em Arquitetura, publicou o livro City of Bits, no qual apresentava uma visão de como seria o futuro com o advento da Internet, que naquela época ainda estava começando a se popularizar, após ter surgido no meio acadêmico. O livro descrevia o teletrabalho e os efeitos que ele teria no ambiente doméstico e urbano. Dois anos depois, juntamente com José Duarte, então seu aluno de doutorado, e com o arquiteto e professor Peter Testa, Mitchell organizou uma das primeiras oficinas de projeto com colaboração remota, o Lisbon Charrette, no qual alunos de Arquitetura do MIT e das Universidades de Lisboa e do Porto desenvolveram conjuntamente propostas para um bairro do futuro. O site da disciplina ainda está disponível no link http://web.mit.edu/4.199/www/class/, onde se pode ler o escopo do projeto proposto:

Em um futuro próximo, uma infraestrutura de telecomunicações digital mais rápida e abrangente oferecerá suporte a videoconferências de baixo custo. A consequência mais óbvia do teletrabalho em casa é uma diminuição na quantidade de espaço de escritório centralizado e um aumento no tamanho das casas. Os teletrabalhadores domiciliares precisarão de áreas de trabalho compartilhadas, como salas de reunião, serviços de impressão e pontos de coleta de pacotes próximos às suas residências.

Existe uma desvantagem para o teletrabalho em casa; os funcionários perdem as oportunidades de encontrar colegas de trabalho pessoalmente e de ter interações sociais informais com eles. Por este motivo, é improvável que os locais de trabalho centralizados desapareçam totalmente. Os trabalhadores tenderão a dividir seu tempo entre o teletrabalho domiciliar e uma forma modificada de local de trabalho centralizado - provavelmente com espaços de reunião e áreas de trabalho em grupo.

Por outro lado, existem alguns benefícios potenciais muito interessantes. As áreas residenciais ganham maior população durante o dia e as oportunidades de interação social dentro da vizinhança aumentam. 
Mas há poucos precedentes diretos a recorrer. Nossa tarefa, neste projeto, é gerar algumas possibilidades interessantes para o futuro e demonstrar as formas arquitetônicas e urbanas que essas possibilidades podem render. (Site da disciplina 4.199 do MIT, 1997, tradução nossa).

Como podemos ver acima, já existia a consciência de que algum dia iríamos trabalhar desde casa, não necessariamente por causa de alguma pandemia, e que essa mudança traria também consequências para nossos hábitos sociais e nossos espaços domésticos e urbanos. No Lisbon Charrette, os participantes trabalharam e colaboraram remotamente, para pensar como seria a vida e a cidade quando a maioria das pessoas passasse também a trabalhar e a colaborar dessa maneira.

A partir dessa experiência, dois artigos científicos foram publicados em coletâneas dedicadas às novas habilidades necessárias para a inovação e ao desenvolvimento inclusivo (BENTO et al. 2002; BENTO et al. 2004). O primeiro deles começava apresentando um cenário de trabalho em que equipes geograficamente distribuídas participavam de projetos colaborativamente:

O projeto de arquitetura é geralmente uma atividade colaborativa, envolvendo o trabalho cooperativo de especialistas de diferentes disciplinas. Além disso, as atividades de projeto frequentemente requerem a reunião de equipes que estão geograficamente distribuídas. Nesses casos, é de grande interesse estabelecer os meios - conceitos, metodologias, ferramentas e modelos - que permitirão a realização do projeto colaborativo distribuído. (BENTO et al., 2002, p. 93, tradução nossa).

Os artigos ainda descrevem os recursos utilizados no processo colaborativo, como modelos geométricos digitais e fotografias da área de intervenção sobre as quais os participantes rabiscavam conjuntamente as hipóteses de projeto. Como a Internet ainda era muito limitada naquela época, as Universidades utilizavam sistemas de videoconferência dedicados (Point-to-Point), mas já se imaginava que essa a Internet se tornaria mais rápida e que sistemas de videoconferência se tornariam acessíveis para o uso doméstico, como o que vemos hoje. Bento et al. (2002) ainda propõem um framework para esse tipo de colaboração, apontando as dificuldades encontradas e as soluções possíveis. Uma das dificuldades descritas era a diferença cultural entre os projetistas e os clientes, que poderia ser amenizada por meio de uma boa quantidade de informações iconográficas e textuais a respeito do local do projeto.

Outra experiência semelhante organizada pelo MIT nos anos de 2000 e 2001, da qual tive a oportunidade de participar como assistente de ensino do professor Michael Dennis, foi o Sarajevo Workshop ${ }^{1}$, envolvendo alunos de Istambul, Sarajevo e Boston ao longo de dois semestres. O objetivo era desenvolver propostas para a reconstrução do centro de Sarajevo, que havia sido destruído pela guerra. Também em 2001, juntamente com os professores Terry Knight e Ryusuke Naka, além da colega Miranda McGill, organizamos o MIT/Miyagi Remote Collaborative Workshop², com uma universidade no Japão, ao longo de duas semanas. Nesse workshop, cujos resultados foram publicados em Celani (2002), testou-se a hipótese de que o uso de um sistema baseado em regras (a gramática da forma) facilitaria o processo remoto, pois ao estabelecer inicialmente regras em comum acordo, os projetistas teriam maior facilidade em projetar colaborativamente. Um artigo posterior de Beamish (2002) analisou essas duas experiências, comparando-as a outras 2 também desenvolvidas no MIT. Beamish enfatiza a importância de se introduzir esse tipo de ambiente colaborativo na formação de arquitetos, em um contexto de crescente internacionalização do trabalho:

\begin{abstract}
O atelier de projeto é um importante componente da formação em arquitetura. Tradicionalmente, ele envolve um número relativamente pequeno de estudantes que trabalham individualmente sob a supervisão de um professor. Com as mudanças globais, entretanto, surge a necessidade de que arquitetos e estudantes de arquitetura aprendam a trabalhar e a colaborar em um ambiente cada vez mais internacional, poliglota e multicultural. As tecnologias de informação e de comunicação podem ajudar, oferecendo aos ateliers de projeto a oportunidade de serem realizados em uma escala global, com participantes de diversas partes do mundo e de diferentes culturas. (BEAMISH, 2002, p. 133, tradução nossa).
\end{abstract}

Os experimentos em colaboração remota de projeto desenvolvidos no MIT na virada do século mostraram que esse tipo de interação entre projetistas era viável e que poderia atender a uma nova demanda por parte do setor de arquitetura, engenharia e construção. Os altos custos envolvidos naquela época, relativos ao acesso dedicado para videoconferências, foi diminuindo gradativamente, ao mesmo tempo em que mais escritórios buscavam colaborações internacionais ou outsourcing de mão de obra. Uma das principais barreiras, tanto no âmbito acadêmico como profissional, foi o idioma e esse tipo de colaboração acabou ocorrendo predominantemente nos países de língua inglesa. Nos dias de hoje, é comum, em grandes escritórios de arquitetura, o desenvolvimento de projetos por equipes multidisciplinares distribuídas em diferentes lugares do mundo. O webinar The Morpheus Hotel: From Design to Production ${ }^{3}$ ilustra muito bem esse processo, incluindo desde os arquitetos do escritório Zaha Hadid Architects até os engenheiros, 
empreiteiros e fabricantes de elementos construtivos em diferentes partes do mundo, e mostra que essa habilidade já pode ser considerada essencial para os arquitetos do século XXI.

\section{ALGUNS EXEMPLOS DE PROJETO COLABORATIVO REMOTO EM 2020}

Quando a Unicamp decretou a suspensão das atividades presenciais, em 13 de março de 2020, apenas uma aula havia sido dada na disciplina de Projeto do $10^{\circ}$ semestre do curso de Graduação em Arquitetura e Urbanismo, intitulada Verticalidade. Além de mim, faziam parte da equipe de instrutores o arquiteto Sávio Jobim, do escritório binacional Triptyque, dois assistentes de ensino, o mestrando Verley Côco Junior e o doutorando Filipe Campos, e o monitor de graduação Rafael Kenzo. Sávio participava da disciplina na qualidade de Professor Especialista Visitante em Graduação, um programa criado há cerca de dez anos pela Pró-Reitoria de Graduação da Unicamp, que tem como objetivo permitir que profissionais de grande destaque atuem como professores ao lado do corpo docente permanente da Universidade, contribuindo para a atualização dos professores e para a qualificação das disciplinas práticas.

Juntamente com os assistentes da disciplina, rapidamente avaliamos as alternativas existentes de aplicativos gratuitos que permitissem a várias pessoas desenhar em uma mesma tela simultaneamente, a compartilhar e visualizar modelos geométricos digitais, a gravar aulas e apresentações, a fazer transmissões ao vivo, etc. Testamos diferentes periféricos para desenhar sobre a tela e aprendemos a usar o Miro, o Modelo, o Jam Board, o Loom, o Zoom, o Streamyard e outros. Trabalhando em um escritório com sedes em São Paulo e Paris, e portanto habituado a trabalhar com equipes internacionais por meio de colaboração remota, Sávio não teve a menor dificuldade em se adaptar à nova realidade. Rapidamente percebemos que as aulas expositivas funcionavam melhor quando gravadas, de modo que os alunos pudessem revê-las em seu próprio ritmo, e descobrimos que as assessorias de projeto e as apresentações de trabalho levavam muito mais tempo quando feitas online. Substituímos as apresentações síncronas pela gravação de vídeos e aos poucos todos acabaram vendo vantagens nas assessorias online, durante as quais conseguíamos fazer uso de diferentes mídias simultaneamente - desenhos técnicos e a mão livre, imagens de modelos geométricos digitais, fotografias de maquetes físicas e de projetos referências, simulações computacionais de vento e energia térmica, informações textuais e muitos post-its virtuais; tudo devidamente gravado como documentação do processo de projeto (Figura 1).

Figura 1: Processo colaborativo online.

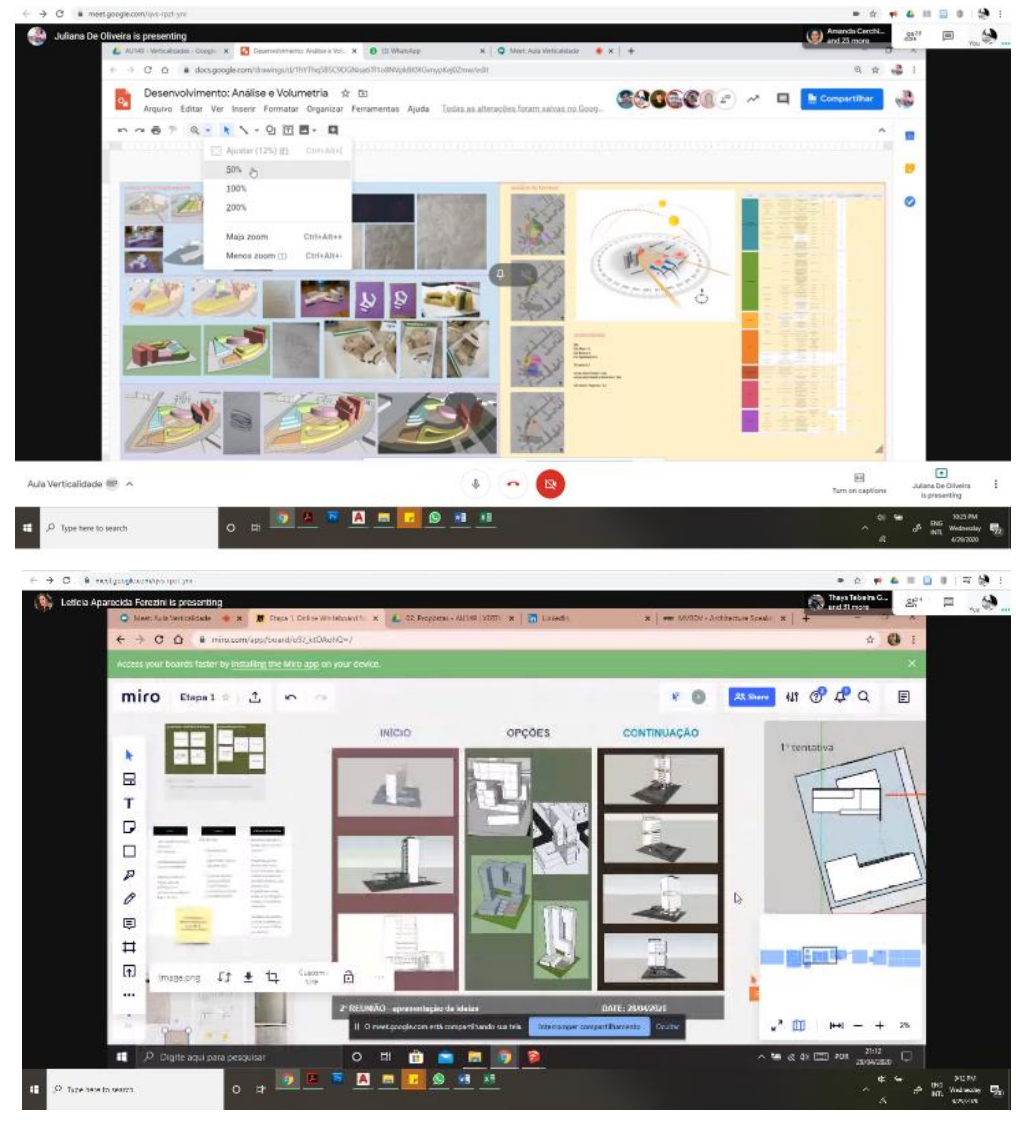

Fonte: Autora. 
$\mathrm{Na}$ apresentação final da disciplina, o arquiteto Sávio convidou 3 arquitetos do escritório Triptyque (Ana Castro, Alice Sallustro e Rafael Igayara) para avaliarem os trabalhos desenvolvidos (Figura 2). Essas pessoas dificilmente teriam se deslocado de São Paulo até Campinas para comentar os trabalhos de alunos de graduação da Unicamp. Contudo, com todos em quarentena, isso pode ocorrer e contribuiu enormemente para a formação dos alunos.

Figura 2: Trabalhos desenvolvidos por algumas equipes da disciplina Verticalidade.

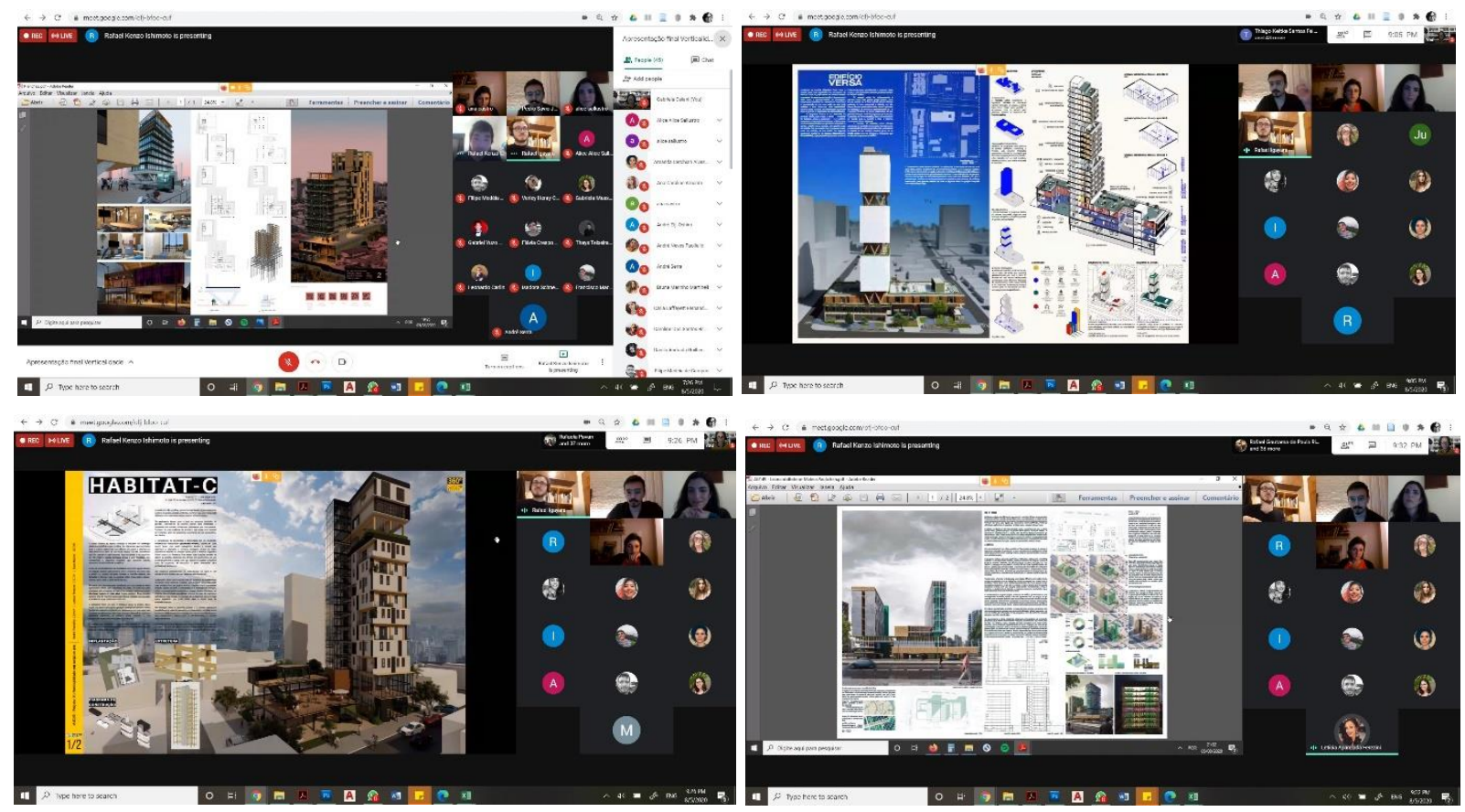

Fonte: Autora.

Outra experiência interessante ao longo de 2020 foi o workshop A quadra do futuro, que fez parte do evento internacional Digital Futures World 4 , promovido pela Universidade Tongji, de Xangai. O workshop teve como objetivo aplicar a modelagem paramétrica ao desenho urbano, considerando diferentes parâmetros de sustentabilidade. Além da autora e do professor Carlos Vaz, da UFSC, participaram como instrutores 8 pesquisadores especializados em diferentes aspectos do desenho urbano: Carme Machí Castañer (Sistemas de drenagem), Filipe Campos (Conforto ambiental), Gustavo Campos de Faria (Mídias móveis e espaços urbanos), Luciana Ferreira (Ilha de calor), Marcela Noronha (Mobilidade ativa), Natalia Queiroz (Energia fotovoltaica), Patrícia Sanches (Quadras verdes compactas) e Robson Canuto (Densidade e uso do solo). O workshop teve 25 participantes, divididos em 5 equipes, que trabalharam em tempo integral ao longo de uma semana (de 27 de junho a 3 de julho de 2020). Tanto os alunos como os instrutores estavam distribuídos geograficamente por diferentes estados brasileiros, e a colaboração ocorreu apenas por videoconferências e com o uso de ambientes online como o Miro. As aulas teóricas foram todas gravadas e disponibilizadas em um site ${ }^{5}$, enquanto os momentos de encontro eram destinados a discussões sobre os projetos, sempre transmitidas pelo youtube. Os resultados mostraram que, além de terem conseguido colaborar remotamente, os participantes conseguiram chegar a resultados muito interessantes.

Uma terceira experiência, em disciplina de graduação de projeto urbano, oferecida neste segundo semestre de 2020, implementa características das duas experiências anteriores. A disciplina está sendo oferecida conjuntamente entre a Unicamp e a UFSC, tendo como professores, de um lado a autora e a pós-doutoranda Patrícia Sanches, e do outro os professores Carlos Vaz e Maíra Felippe. As equipes, sempre compostas por alunos das duas universidades, puderam optar entre desenvolver um projeto para Florianópolis ou para Campinas. Aulas gravadas são disponibilizadas semanalmente no site da disciplina ${ }^{6}$, e os horário de aula é usado exclusivamente para assessorias e para discussão dos resultados.

\section{CONSIDERAÇÕES FINAIS}

Muitas vezes, situações adversas acabam servindo para provocar mudanças disruptivas em culturas cristalizadas, como a do atelier de projeto em Arquitetura e Urbanismo. Nos anos 1990 e 2000, ficaram muito conhecidas as histórias de professores de projeto que não permitiam que seus alunos utilizassem 0 computador para elaborar seus projetos. A dificuldade e custo da plotagem e a falta de computadores nos 
ateliers justificavam, em parte, essa aversão. A partir da década de 2010, quando os notebooks se tornam mais acessíveis e presentes nos cursos de graduação, alguns professores ainda reclamavam da dificuldade em acompanhar o vai-e-vem rápido do zoom e a dificuldade em lidar com as diferentes escalas por parte dos alunos. Mesmo quando as cortadoras a laser se tornaram comuns nas escolas de Arquitetura, alguns professores ainda reclamaram da automatização da produção de maquetes, argumentando que o contato com o papelão e o estilete seria importante para a formação dos arquitetos. Em 2020, contudo, a mudança foi compulsória. Não tivemos alternativa, a não ser nos adaptar. Mas essa mudança pode ter trazido a oportunidade de implementar definitivamente práticas que nunca haviam chegado a ser institucionalizadas mais amplamente na virada do século, mas que certamente passarão a ser consideradas habilidades fundamentais para os arquitetos do século XXI.

\title{
4 REFERÊNCIAS
}

BEAMISH, A. Strategies for International Design Studios - Using Information Technologies for Collaborative Learning and Design. In: Salama, A. M. A., O'Reilly, W., Noschis, K. (Eds.). Architectural Education today - Cross-cultural perspectives. Lausanne: Ecole Polytechnique Fédérale de Lausanne. pp.133-142, 2002. Disponível em: https://books.google.com.br/. Acesso em: 26 de novembro de 2020.

BENTO, J.; DUARTE, J. P.; HEITOR, T.; HEITOR, M. V. Remote Collaborative Design: Cooperation in Engineering and Architecture. In: J. Bento, J. P. Duarte, M. V. Heitor, W. J. Mitchell (Eds.). Collaborative Design and Learning-Competence Building for Innovation. Westport: Praeger Publishers. pp.247-263, 2004. Disponível em: https://books.google.com.br/. Acesso em: 26 de novembro de 2020.

BENTO, J.; HEITOR, T.; DUARTE, J. P. Remote collaborative design: The Lisbon charrette experience. In: P. Conceição, D. Gibson, M. Heitor, G. Sirilli, F. Veloso (Eds.). Knowledge for inclusive development (Cap.4). Connecticut: Quorum Books, Greenwood Publishers. pp.93-110, 2002. Disponível em: https://books.google.com.br/. Acesso em: 26 de novembro de 2020.

CELANI, G. MIT-MIYAGI Workshop 2001 - An educational experiment with shape grammars and computer applications. International Journal of Design Computing, Key Centre of Design Computing, Faculty of Architecture, University of Sydney, Sydney, v. 3, p. 1-5, 2002. Disponível em:

https://web.archive.org/web/20050322201055fw /http:/www.arch.usyd.edu.au/kcdc/journal/vol3/celani/abstract.htm. Acesso em: 26 de novembro de 2020.

\author{
NOTAS \\ ${ }^{1}$ https://stuff.mit.edu/afs/athena/course/4/4.175/www/ \\ 2 http://www.mit.edu/ 4.184/ \\ ${ }^{3}$ https://vimeo.com/203509846 \\ ${ }^{4}$ https://www.digitalfutures.world/workshops-americas-blog/celani \\ ${ }^{5}$ https://sites.google.com/unicamp.br/aquadradofuturo \\ ${ }^{6}$ https://sites.google.com/view/disciplinaintegrada
}

NOTA DO EDITOR (*): O conteúdo do artigo e as imagens nele publicadas são de responsabilidade do(s) autor(es). 